\title{
Effect of the Secondary Phase on the Corrosion of Al-Zn-Mg-Cu Alloy
}

\section{Hui Chen ${ }^{1}$, Xiaoye Zhang ${ }^{1,2}$ and $Y a L^{i^{*}}$}

${ }^{1}$ Guangdong Diankeyuan Energy Technology co., Ltd, China

${ }^{2}$ Electric Power Research Institute of Guangdong Power Grid co., Ltd., China

${ }^{3}$ State Key Lab of Powder Metallurgy, Central South University, China

\begin{abstract}
A non-heat treatment way was applied to study the effect of the secondary phase on the corrosion of $\mathrm{Al}-\mathrm{Zn}-\mathrm{Mg}-\mathrm{Cu}$ alloy in order to exclude the effect of variation of grain size. The area ration of corrosion pits and secondary phase (150 samples) was used to characterize the corrosion degree of secondary phase after Intergranular Corrosion test for a constant period. Then the effect of size and distribution of secondary phase was determined by using the SEMEDS and EPMA equipment, the Electrochemical test and the Image-pro plus software after immersion test. The results show that the corrosion resistance of $\mathrm{Al}-\mathrm{Zn}-\mathrm{Mg}$-Cu alloys is positive related to the size of secondary phase. The sparse or dense phase distribution on and within grain boundary retard the pit initiate and extend along the grain boundary, so it increases the corrosion resistance of $\mathrm{Al}-\mathrm{Zn}-\mathrm{Mg}-\mathrm{Cu}$ alloy.
\end{abstract}

Keywords

Al-Zn-Mg-Cu alloy, Secondary phase, Corrosion

\section{Introduction}

Al-Zn-Mg-Cu series alloys are extensively used in aerospace and transportation because of their exceptional combination of low density, high ductility and high strength [1-3]. The excellent mechanical properties and good electrochemical properties are attributed to the well combination between the precipitated strengthen phase and refined grain size, which are mainly formed during the deformation and heat treatments process [4]. However, the mechanical properties are usually negative related with the corrosion resistance properties for this type alloy [5]. The high strength of Al-Zn-Mg-Cu alloy is attribute to the appropriate size and distribution of secondary phase after a series deformation and heat treatments process, but this heterogeneity of atomic composition originate from secondary phase also renders the alloy prone to localized corrosion, the structure material would easily to failure in service $[6,7]$. There is a strong correlation between local corrosion behaviors of $\mathrm{Al}-\mathrm{Zn}-\mathrm{Mg}-\mathrm{Cu}$ alloy and intermetallic. Pitting corrosion is one of the most common corrosion behaviors of localized corrosion, and can lead to more serious corrosion

*Corresponding author: Ya Li, State Key Lab of Powder Metallurgy, Central South University, Changsha, China, Tel: $+86-15274867157$

Accepted: September 11, 2020; Published: September 13, 2020

Copyright: (c) $2020 \mathrm{Chen} \mathrm{H}$, et al. This is an open-access article distributed under the terms of the Creative Commons Attribution License, which permits unrestricted use, distribution, and reproduction in any medium, provided the original author and source are credited.

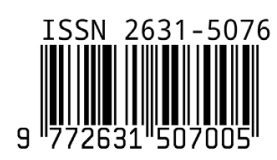

Chen et al. Int J Metall Met Phys 2020, 5:058 
behavior, such as Intergranular Corrosion (IC), exfoliation corrosion and stress corrosion cracking [8]. In Al-Zn-Mg-Cu alloy, secondary phases (such as $\mathrm{MgZn}_{2}$ phase, $\mathrm{Al}_{2} \mathrm{CuMg}$ phase and $\mathrm{Al}_{7} \mathrm{Cu}_{2} \mathrm{Fe}$ phase) are considered as the initial site of pitting corrosion because of the strong galvanic coupling with the Al-matrix. Whether the intermetallic particles act as anode or cathode depending their components and chemical composition. The cathode particles would be more harmful for the corrosion resistance of aluminum alloy, because the cathode intermetallic particles can be easily fell off from the Al-matrix during the corrosion circumstances [9]. Therefore, studying the effect of secondary phase on the corrosion behaviors of $\mathrm{Al}-\mathrm{Zn}-\mathrm{Mg}-\mathrm{Cu}$ alloy has a big practice significance.

The extensive research has been documented to study the effect of secondary phase on the corrosion behaviors of Al-Zn-Mg-Cu alloys [10-12]. These researches mainly can be divided into three aspects: Corrosion mechanism, phase structure, size and distribution of phase. For instance, Yuanwei Sun, et al. [13] investigated the localized corrosion behavior of $\mathrm{Al}_{7} \mathrm{Cu}_{2}$ Fe phase in $\mathrm{Al}-\mathrm{Zn}-\mathrm{Mg}$-Cu-Zr alloy. Atomic force microscopy was used to measure the potential difference between $\mathrm{Al}_{7} \mathrm{Cu}_{2} \mathrm{Fe}$ phase and Al matrix, the result shows that the $\mathrm{Al}_{7} \mathrm{Cu}_{2} \mathrm{Fe}$ phase acts as cathode expect to the Al-matrix during the Intergranular Corrosion test. Yu Shuang, et al. [9] studied the corrosion behavior of $\beta^{\prime}$ phase in $\mathrm{Mg}$ $10 \mathrm{Gd}-3 \mathrm{Y}-0.4 \mathrm{Zr}$ alloy during aging Treatment, the results show that the corrosion behavior of this alloy is mainly attributed to the multilayer structure of $\beta^{\prime}$, the rare earth appears zigzag monolayers in $\beta^{\prime}$ phase along the direction of $\left[\begin{array}{lll}1 & 0 & 0\end{array}\right]_{\beta^{\prime \prime}}$ and three layers of $\mathrm{Mg}$ are arranged between each two RE layers, so the dissolution of the RE monolayers occurs preferentially in $\beta^{\prime}$ phase during corrosion. J Wanget, al. [14] investigated the corrosion pitting initiation for different sizes of S-phase in 2024Al alloy during the solid solution process, the results show that the S-phases triggers the local dissolution of the surrounding Al matrix with the increasement of the size. What's more, K.D. Ralston, et al. [15] studied that the effect of phase size on the yield strength-pitting corrosion relationship in Al-CuMg alloys, the results show that a precipitate size range exists where the inverse correlation between strength and corrosion resistance can be broken. Besides, there are also large numbers of research proceeded in terms of the combination effect of secondary phase and grain size on the corrosion of metal alloy [8,16-18].

However, although the research on the phase corrosion behavior has obtained excellent progress, the limitation of these researches is the single experiment way, i.e. the heat treatment process. But the structure, phase size and grain size wouldn't individually change during the solid solution or aging heat treatment, it brings a little discrepancy when the research point is only one of the above variations, such as the secondary phase or grain size. Nevertheless, the dissolution activity varies from one particle to another particle, which hinders understanding the mechanism of pitting initiating and propagation in Al-Zn-Mg-Cu alloy [19]. For instance, the electrochemical role of nanoscale S-phase at the initial corrosion stage has been investigated, a critical size of about $10 \mathrm{~nm}$ is determined below which S-phases are free of pitting corrosion [20].

Therefore, a novel way was used to study the effect of secondary phase on the corrosion of Al$\mathrm{Zn}-\mathrm{Mg}$-Cu alloy. During this work, the effect of secondary phase on the corrosion of $\mathrm{Al}-\mathrm{Zn}-\mathrm{Mg}-\mathrm{Cu}$ was investigated by using a non-heat treatment way (excepting some samples would only be conducted to pre-heat treatment before experiment) to exclude the effect of grain size variation. The ration of corrosion pit and secondary phase (150 samples) was used to characterize the corrosion degree of secondary phase after Intergranular Corrosion test. Then the effect of size and distribution of secondary phase were determined by using the SEM-EDS and EPMA equipment and the Image-pro plus software. What's more, the relationship between the composition of solute atoms and the volume of secondary phase, and the evolution law of atomic concentration in secondary phase and surrounding region during IC test was also determined.

\section{Experimental Procedures}

\section{Materials preparation}

The raw materials were melted at $800^{\circ} \mathrm{C}$ in electrical resistance furnace. The melt was poured at a temperature of $780{ }^{\circ} \mathrm{C}$ into a rectangular permanent steel mold to obtain the cast ingot. The melting process was completed in Hunan Business College, China. The chemical compositions of the experimental alloy are shown in Table 1. The ingot was conducted a two-stage homogenization (400 ${ }^{\circ} \mathrm{C} / 12 \mathrm{~h}+470{ }^{\circ} \mathrm{C} / 12 \mathrm{~h}$ ) before deformation process. 
Table 1: Chemical composition of aluminum alloy Al-Zn-Mg-Cu (wt. \%).

\begin{tabular}{|l|l|l|l|l|l|l|l|l|l|}
\hline $\mathrm{Si}$ & $\mathrm{Fe}$ & $\mathrm{Zn}$ & $\mathrm{Cu}$ & $\mathrm{Mg}$ & $\mathrm{Zr}$ & $\mathrm{Cr}$ & $\mathrm{Ti}$ & $\mathrm{Mn}$ & $\mathrm{Al}$ \\
\hline 0.076 & 0.083 & 6.43 & 2.24 & 1.98 & 0.12 & 0.010 & 0.039 & 0.003 & Bal. \\
\hline
\end{tabular}

After the completion of homogenization treatment, the alloy was directly suffered water quenching. The material used in this study is hot-rolled Al-Zn$\mathrm{Mg}-\mathrm{Cu}$ plate (the initial thickness of plate was 500 $\mathrm{mm}$ and the rolled starting temperature is $460{ }^{\circ} \mathrm{C}$, the roll was pre-heated up to $300^{\circ} \mathrm{C}$. During rolling process, the rolled reduction is $84 \%$, thus the thickness of finished product is $80 \mathrm{~mm}$, and the finished temperature of plate is approximately $320^{\circ} \mathrm{C}$ ). The rolling process was performed in the State Key Laboratory of High Performance and Complex Manufacturing, Central South University.

Several samples with across-section of $10 \times 10$ $\mathrm{mm}$ and a thickness of $5 \mathrm{~mm}$ were cut from the central surface of the plate. It is worthy note that the samples were cut from the same position in order to let these samples possess the similar grain size. Afterwards, samples were progressively ground to 1500 grit with SiC paper followed by $1 \mu \mathrm{m}$ diamond suspension polishing for the after using. Besides that, some samples were suffered a pre-solid solution process in order to dissolve the small and dispersive phases before immersion test.

\section{Microstructural analysis}

To characterize the morphology, distribution and concentration of secondary phase, the ZEISS EVO MA10 Scanning Electron Microscopy (SEM) with a Tungsten filament and Energy Dispersive Spectrometer (EDS) analysis were carried out on as-polished surfaces, the accelerating voltage is 20 kV. The Electron Probe Microanalysis (EPMA) 1720 series instrument was used to measure the distribution map of the solute atom concentration, the resolution of which is approximate $5 \AA$ and the acceleration voltage is $20 \mathrm{kV}$. What's more, the size of secondary phase was gauged by using Image-pro plus software.

\section{Immersion and electrochemical polarization testing}

Before immersion testing, all samples were prepared to a $1 \mu \mathrm{m}$ finished diamond polishing. Immersion testing was conducted in Intergranular Corrosion (IC) solution $\left(57 \mathrm{~g} \mathrm{NaCl}+10 \mathrm{ml} \mathrm{H}_{2} \mathrm{O}_{2}\right.$ then dilution by water to $1 \mathrm{~L}$ solution) for $0.5 \mathrm{~h}, 1 \mathrm{~h}, 1.5$ h, $2 \mathrm{~h}, 2.5 \mathrm{~h}, 3 \mathrm{~h}$ respectively. After immersion, the cleaning of sample surfaces was done by immersion and agitation in $20 \%$ nitric acid $80 \%$ distilled water for about $1 \mathrm{~min}$ till the corrosion products fell off from the sample surface and left distinct corrosion pits. Followed by a water rinse and ethanol washed away the corrosion products remain on the surface. This processing was satisfactory for removal of corrosion product without causing deleterious damage to the alloy surface.

Electrochemical measurement was conducted by using a standard three-electrode system electrochemical workstation (CHI660E, Shanghai chenhua instrument co., LTD, China) in 3.5 wt.\% NaCl aqueous solution at $25 \pm 1{ }^{\circ} \mathrm{C}$. The hot rolled specimens were taken along the cross section and the working electrode with an exposed surface of 1 $\mathrm{cm}^{2}$. A saturated calomel reference electrode (SCE) and a platinum plate counter electrode (CE) were applied with the specimen working electrode (WE) to carry out the electrochemical tests. The polarization curves were acquired at the sweep rate of $1 \mathrm{mV}^{*} \mathrm{~s}^{-1}$ with the potential changed from $-1.6 \mathrm{~V}$ to $-0.2 \mathrm{~V}$. Immersion and electrochemical polarization tests were duplicated for three times of each alloy to guarantee the repeatability.

\section{Corrosion morphology observation}

The microstructure and morphology of the immersion-tested samples was observed using SEM equipment. The concentration distribution of solute atoms after IC was observed by using SEM-EDS and EPMA equipment. The size of secondary phase and corrosion pits was gauged by Image-pro plus software.

\section{Results}

\section{Microstructure evolution}

The localized microstructure evolution of the samples after immersed IC solution for $1 \mathrm{~h}$ was determined by in-situ SEM and EDS observation methods as shown in Figure 1, and the chemical concentration of the phase point " $D$ ", " $E$ " and " $F$ " are shown in Table 2. Figure $1 \mathrm{a}$ is the initial microstructure of samples before IC test, it can be obtained that $\mathrm{Al}_{7} \mathrm{Cu}_{2} \mathrm{Fe}$ (Irregular and bulky), S-phase 


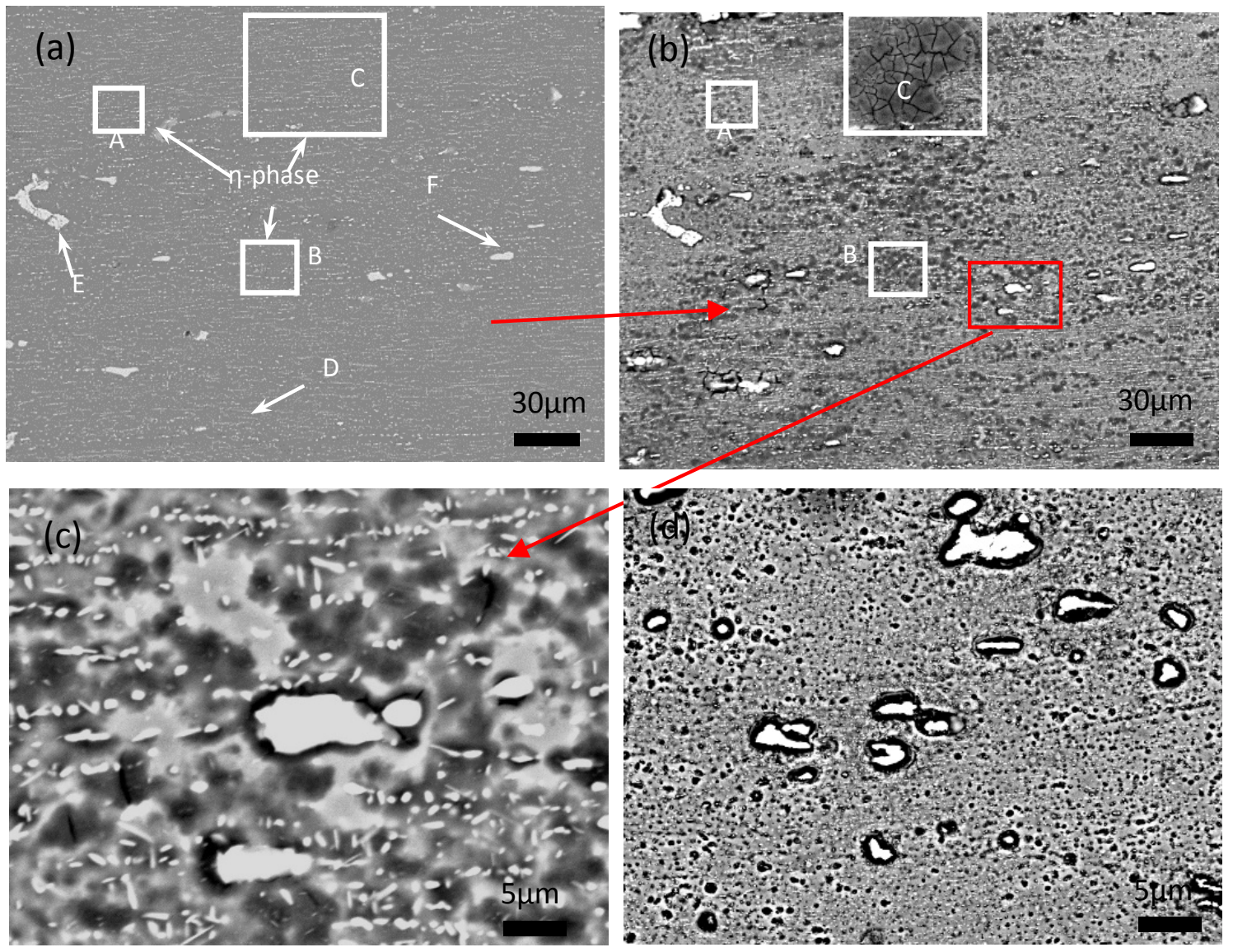

Figure 1: The corrosion morphology of samples after IC for different time: (a) Before immersion test; (b) After immersion test for $1 \mathrm{~h}$; (c) Local magnitude image of the red box in (b); and (d) After immersion test for $2 \mathrm{~h}$.

Table 2: Atomic concentration of the secondary phases.

\begin{tabular}{|l|l|l|l|l|l|l|l|}
\hline Points & Morphology & Al & Zn & Mg & Cu & Fe & Phase \\
\hline D & Circular dispersive & 72.81 & 7.16 & 8.38 & 11.65 & - & $\eta\left(\mathrm{MgZn}_{2}\right)$ \\
\hline E & Irregular and bulky & 70.49 & 3.16 & - & 17.91 & 8.43 & $\mathrm{Al}_{7} \mathrm{Cu} \mathrm{F}_{2} \mathrm{Fe}$ \\
\hline F & Rod like & 50.29 & 1.86 & 23.79 & 24.07 & - & $\mathrm{S}\left(\mathrm{Al}_{2} \mathrm{CuMg}\right)$ \\
\hline
\end{tabular}

(rod like) and $\eta$-phase (Circular dispersive) all appear white, and the matrix appear grey. What's more, the distribution of $\eta$-phase is small and dispersive, the S-phase and $\mathrm{Al}_{7} \mathrm{Cu}_{2}$ Fe phase are bulky and discretely distributed in Al matrix. Figure $1 \mathrm{~b}$ is the in-situ morphology of samples surface after IC test for $1 \mathrm{~h}$, and Figure $1 \mathrm{c}$ is the enlarged region of the red box in Figure $1 \mathrm{~b}$. It can be seen that the typical morphology of this alloy after IC existed in Figure $1 \mathrm{~b}$ and Figure $1 \mathrm{c}$, such as corrosion pits and mud-cracking (as shown the box " $C$ " in Figure 1b). The core-type structure of the pits implies that the $\eta$-phase and S-phase generally acted as cathode with expect to the Al matrix during IC test. Figure $1 d$ is the corrosion morphology of samples pits after IC for $2 \mathrm{~h}$. It is easy figured out that some small
S-phases and a large number of $\eta$-phases fell off from the matrix and left the corrosion cavities after $\mathrm{IC}$ for $2 \mathrm{~h}$. That means the dispersive $\eta$ phase would more easily fell off from the Al matrix than the bulky S-phase in the Intergranular Corrosion circumstance. And the corrosion degree is more severe (e.g. mud-cracking corrosion) in the region consists of the dispersive $\eta$ phase with respect to that of S-phase. What's more, the remained S-phase and $\mathrm{Al}_{7} \mathrm{Cu}_{2} \mathrm{Fe}$ phase presented obvious core-type structure, and the shapes are similar between the outer pits and core phase.

It is worthy noted that the similar microstructure has the extraordinary different corrosion morphology. For instance, there was no obvious characterization of corrosion was occurred in region 


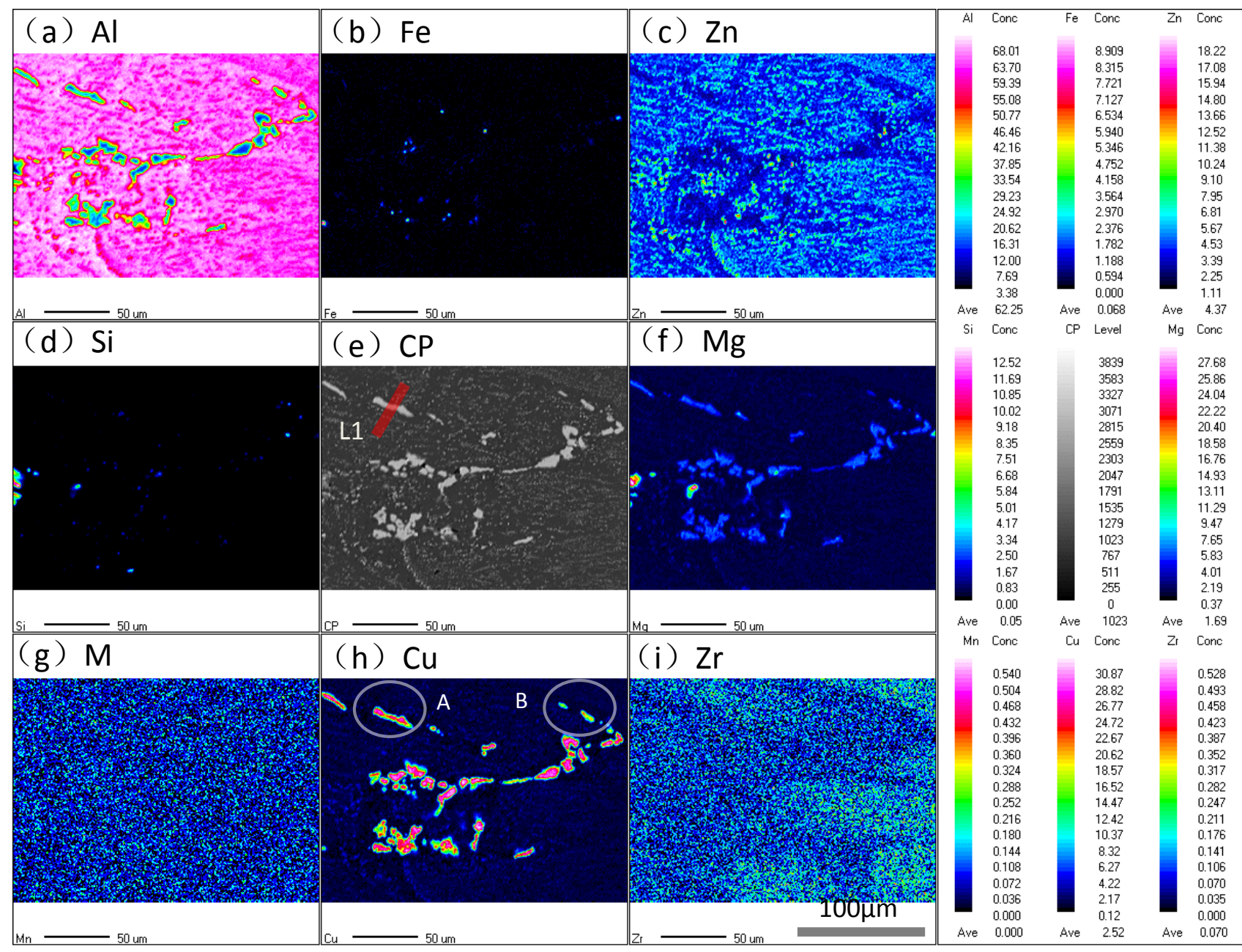

Figure 2: EPMA mapping analysis of the samples before IC test.

" $A$ ", but the opposite results have taken place in region " $B$ " and " $C$ ". Besides, the form of mud-cracking corrosion morphology was observed in region " $C$ ". This mud-cracking initiated at the $\eta$-phase and propagated to the matrix along the grain boundary. What's more, the corrosion pits of bulky S-phase also present core-type structure. And there is no distinct variation of area for the secondary phase after IC test by comparing with images in Figure 1 a and Figure $1 \mathrm{~b}$. For the bulky and irregular $\mathrm{Al}_{7} \mathrm{Cu}_{2} \mathrm{Fe}$ phase, the similar phenomenon (core-type structure) was found during the Intergranular Corrosion test. What's more, there were large differences in terms of corrosion degree in a mesoscopic region as shown in Figure 1c, such as the coexistence of core-type structure, pits and corroded regions. The reason for that will determine in after research.

\section{Evolution of atomic concentration}

EPMA mapping analysis was carried out to intuitively characterize the atomic concentration distribution in constituent particles and matrix before and after IC test, and the results are shown in Figure 2 and Figure 3. It can be found that the contents of $\mathrm{Cu}$ and $\mathrm{Mg}$ are at a high level in bulky $\mathrm{S}\left(\mathrm{Al}_{2} \mathrm{CuMg}\right)$ phase. The contents of $\mathrm{Mg}$ and $\mathrm{Zn}$ are at a high level in dispersive $\eta\left(M g Z n_{2}\right)$ phase with respect to that in matrix, and the content of $\mathrm{Al}$ is at a low level in those particles. The contents of $\mathrm{Fe}$, $\mathrm{Mn}, \mathrm{Si}$ (only a few $\mathrm{Mg}_{2}$ Si-phase exist) and $\mathrm{Zr}$ uniformly distribute in S-phase and matrix. It is worthy noted that the content of main elements in core of particles is higher than that in boundary of particles and matrix. It can also be found that the content of main elements in core of particles is positively related to the volume of these particles, e.g., the content of $\mathrm{Cu}$ in phase of the " $A$ " and " $B$ " regions in Figure 2, The result has also been confirmed in our previous research [21].

Figure 3 is the distribution of atomic concentration in secondary phase and surrounding matrix after IC test for $1 \mathrm{~h}$. Comparing the results before 


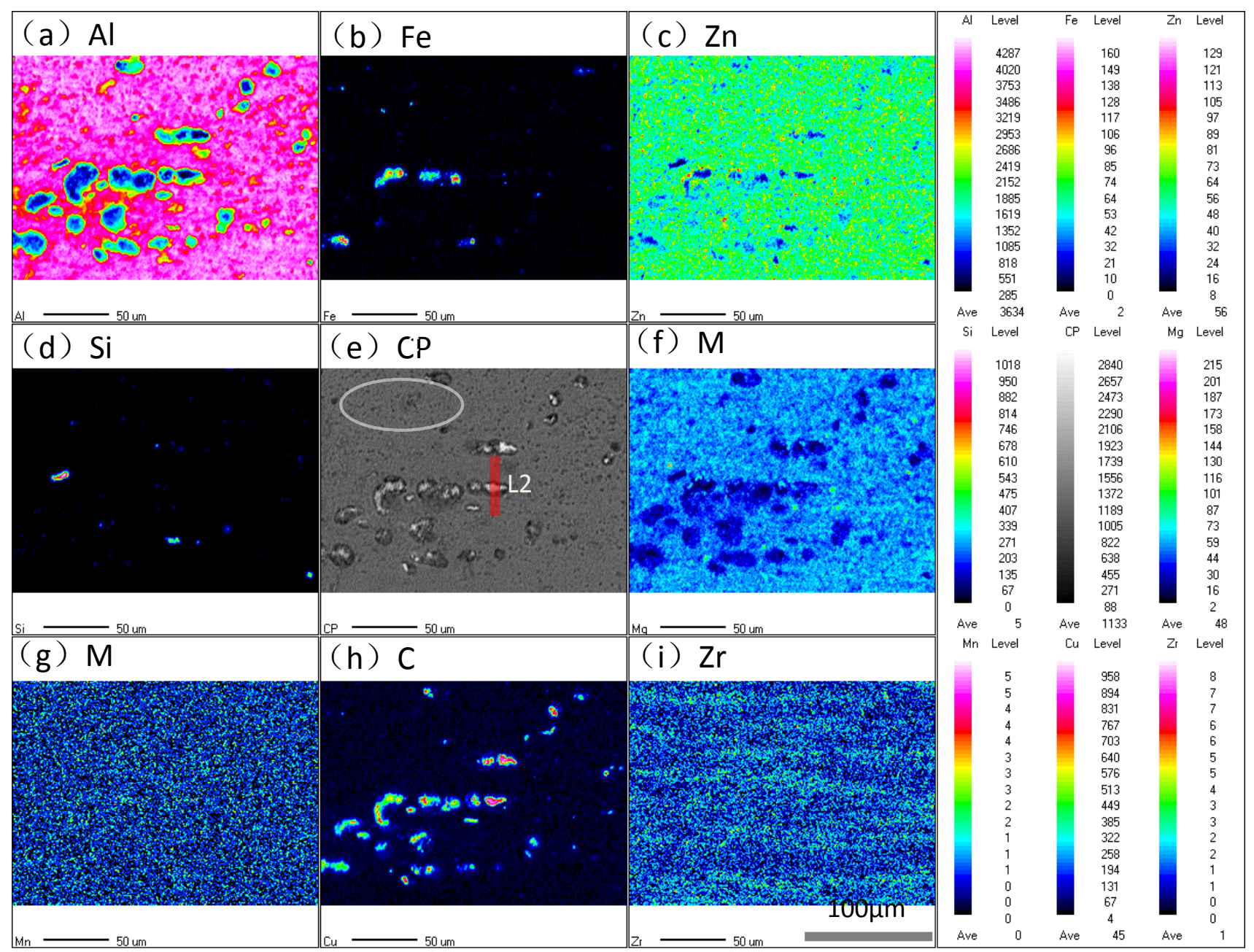

Figure 3: EPMA mapping analysis of the samples after IC test for $1 \mathrm{~h}$.

IC test in Figure 2, the main change of morphology are the dissolution of intermetallic compounds and the formation of the corrosion pits. Besides, the contents of $\mathrm{Mg}$ and $\mathrm{Al}$ in S-phase and corrosion cavity decreased into a low level after IC test, and that of $\mathrm{Cu}$ increased into a high level after IC test. The Liner-Scanning (LS) of EDS was also used to characterize the evolution of atomic concentration in S-phase and adjacent region during IC test, and the results are shown in Figure 4 . The abscissa is the distance from the start point to the scanning point of $L S$, the ordinate is the content of element in S-phase, L1 and L2 in Figure 2 and Figure 3 represent the position of LS by EDS measurement before and after IC test respectively. The black line and red line in Figure 4 represent the profiles of elements before and after IC test respectively.

It can be seen that the concentration of $\mathrm{Mg}$ and Al decreased monotonously in $\mathrm{S}$ phase and adjacent regions, but that of $\mathrm{Cu}$ increased in these regions. It evident that $\mathrm{Mg}$ and $\mathrm{Al}$ in $\mathrm{S}$ phase are mainly pref- erentially dissolved in the process of Intergranular Corrosion. By comparing the relative research before [22-25], it is easy to find out that the Mg element in S-phase acts as anodic with respect to matrix during the corrosion initiation stage, and preferentially dissolved to the IC solution, thus the $\mathrm{Cu}$ element is in a high content in de-alloyed S-phase. Then the Al element in surrounding matrix acts as anodic with respect to the de-Mg S-phase which mainly comprise low content of $\mathrm{Al}$ and high content of Cu element. Ultimately, the de-Mg S-phase would fell off from the matrix when the adjacent matrix all dissolved to the IC solution. By comparing the contents of $\mathrm{Zn}$ and $\mathrm{Mg}$ in $\eta\left(\mathrm{MgZn}_{2}\right)$ phase before and after IC test as shown in Figure 2 and Figure 3, it can be found that the content of $\mathrm{Mg}$ and $\mathrm{Al}$ in $\eta$ phase and surrounding regions decreased after IC and formed the morphology of corrosion pits, but the content of $\mathrm{Zn}$ in $\eta$ phase is basically unchanged. The circle " $\mathrm{C}$ " in Figure 3 main containing the Fe-containing $\left(\mathrm{Al}_{7} \mathrm{Cu}_{2} \mathrm{Fe}\right)$ phases, it can be 

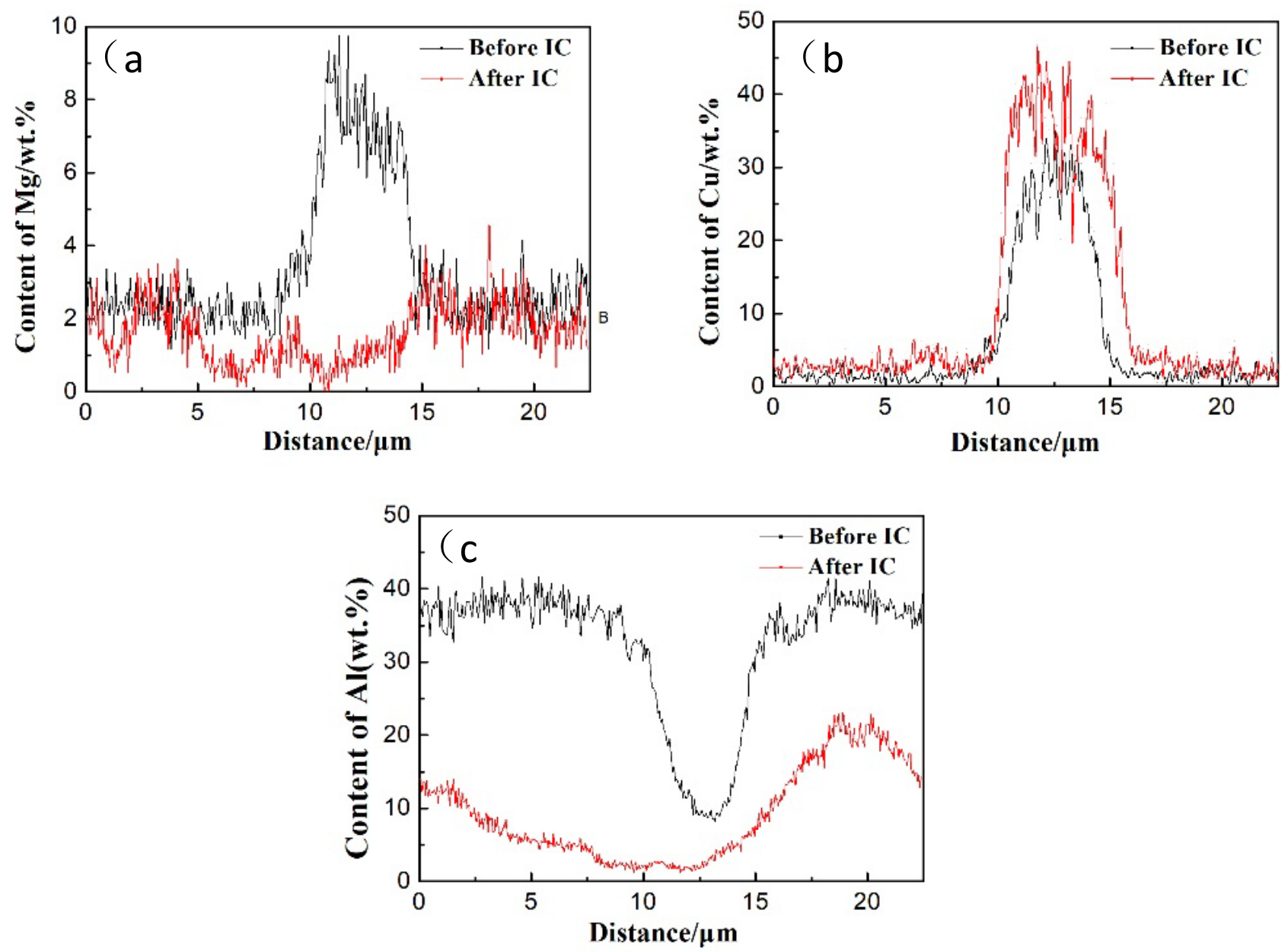

Figure 4: The variation of atomic concentration of: (a) Mg; (b) Cu; (c) Al in S-phase and adjacent region after IC.
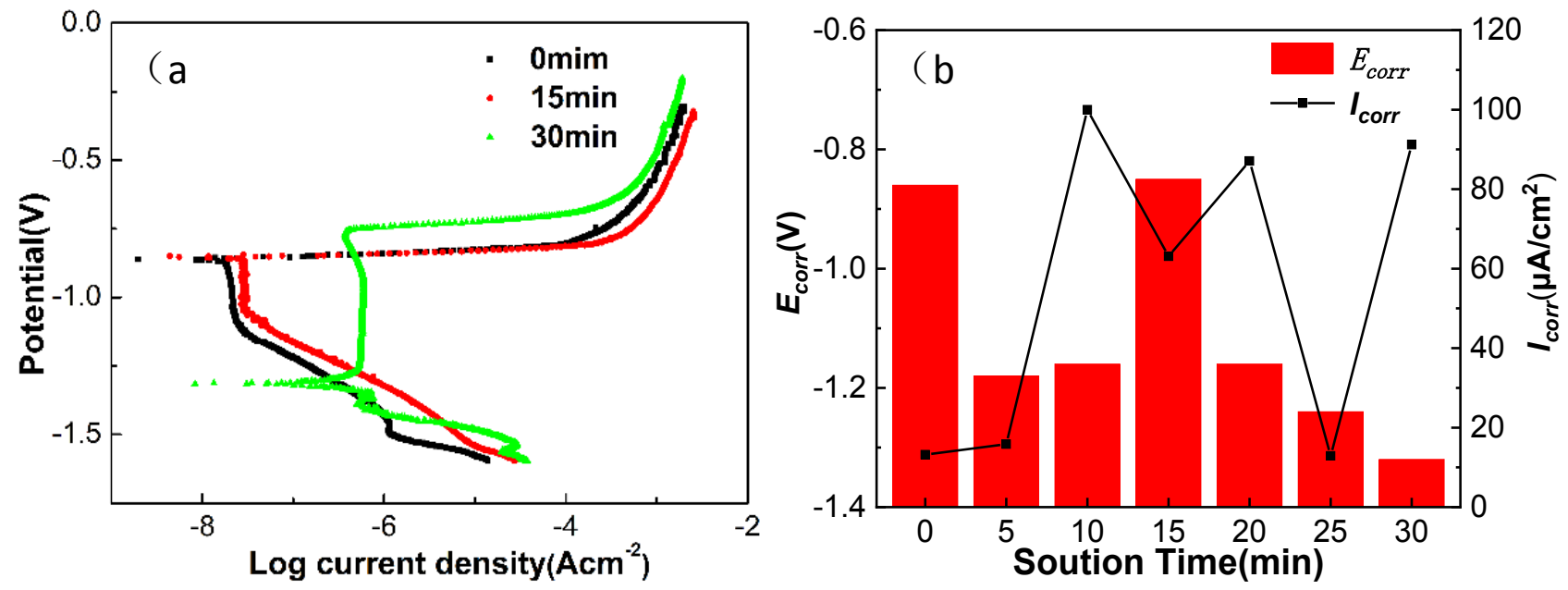

Figure 5: Polarization test of the alloy in $3.5 \mathrm{wt} . \% \mathrm{NaCl}$ aqueous solution: (a) Polarization curves; and (b) Corrosion potential and corrosion current density for samples after solid solution at $470{ }^{\circ} \mathrm{C}$ for different time.

found that the contents of $\mathrm{Fe}$ and $\mathrm{Cu}$ in $\mathrm{Al}_{7} \mathrm{Cu}_{2} \mathrm{Fe}$ phases are also in a high level that means the Al${ }_{7} \mathrm{Cu}_{2} \mathrm{Fe}$ phases acts as cathode with respect to the Al matrix during the IC test.

\section{Electrochemical test}

The aim of this work is to research the effect of secondary phase on the corrosion of $\mathrm{Al}-\mathrm{Zn}-\mathrm{Mg}-\mathrm{Cu}$ 
alloy by using a non-heat treatment way to exclude the effect of the variation of grain size, but some samples need to suffer a pre-solid solution to dissolve the dispersive $\eta$ phase, so the corrosion behavior of samples varies with the solution time should be provided here. What's more, the solid solution process of samples accompanies the dissolution of different kinds of particles, so it can provide the fundament of theoretical analysis about the different corrosion behaviors of different phases. Figure $5 \mathrm{a}$ presents the polarization curves and Figure $6 \mathrm{~b}$ presents the corrosion potential $\left(E_{\text {corr }}\right)$ and corrosion current density $\left(I_{\text {corr }}\right)$ for samples respectively after solid solution at $470^{\circ} \mathrm{C}$ for different time in 3.5 wt.\% $\mathrm{NaCl}$ aqueous solution and the temperature is $25^{\circ} \mathrm{C}$. It can be seen that the corrosion potential is about $-0.86 \mathrm{~V}$ for the hot rolled sample, higher than that of samples during most stages of solid solution. The corrosion potential first decreased and then increased when the alloy was dissolved at 470 ${ }^{\circ} \mathrm{C}$ for 0 15 min, afterwards, the corrosion potential decreased monotonous when the alloy was dissolved exceeded $15 \mathrm{~min}$. The evolution of corrosion current density is almost opposite to that of corrosion potential. However, it is worth noting that the $l_{\text {corr }}$ only occurred a minor shift when the solution time varies from $0 \mathrm{~min}$ to $5 \mathrm{~min}$. Thus, the pre-heat treatment $\left(470{ }^{\circ} \mathrm{C} / 5 \mathrm{~min}\right)$ of some samples has little influence on the corrosion behavior of samples. Due to the aluminum alloy acts as anodic in 3.5 $w t . \% \mathrm{NaCl}$ aqueous, the corrosion resistance and corrosion current density of the alloy are negatively correlated. Consequently, the corrosion resistance of the alloy first decreased and then increased and finally decreased with the solution time when the samples were suffered solid solution at $470{ }^{\circ} \mathrm{C}$ for 0 30 min. Besides that, the corrosion resistant is well performed when the alloy was dissolved at $470{ }^{\circ} \mathrm{C}$ for about $0 \sim 5 \mathrm{~min}$ and $25 \mathrm{~min}$. It also can be seen that there is a passivation zone for the sample after solid solution for $30 \mathrm{~min}$, the possible reason is the forming of the oxide layer during the longtime solid solution at high temperature.

\section{Corrosion behavior-phase size}

To determine the relationship between corrosion resistance and size of constituent particles of Al-Zn-Mg-Cu alloy, about 150 phases (the morphology of one typical sample is shown in Figure 1d) with different sizes were investigated in terms of the area of the secondary phase and the adjacent

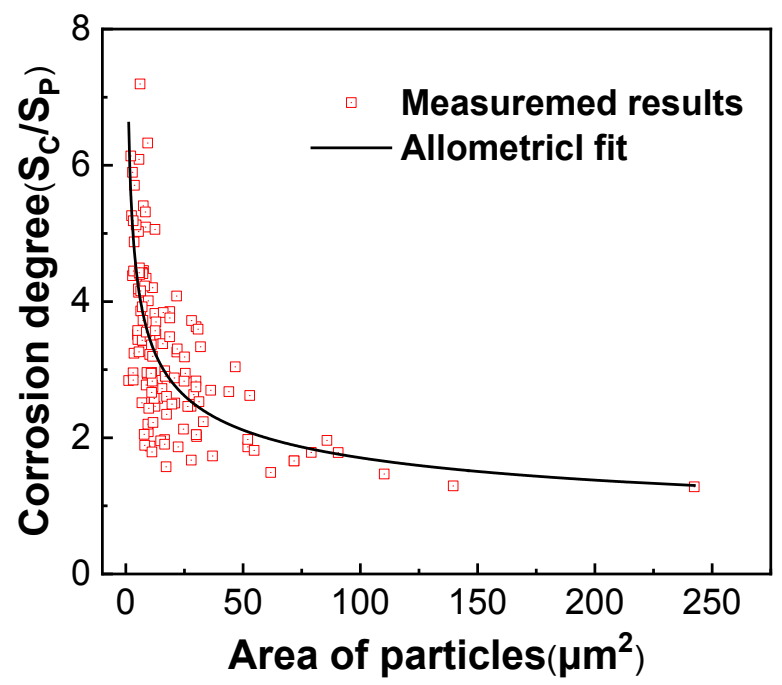

Figure 6: The effect of S-phase size on the corrosion of Al-Zn-Mg-Cu alloy after IC for $2 \mathrm{~h}$ (the corrosion degree is the area ratio of the corrosion pit and the core phase).

pits after IC for $2 \mathrm{~h}$. Due to the data about the size and distribution density of $\mathrm{S}$ phase is easy to collect, all phases chosen were S-phase determined with EDS observation method before test. The final results are shown in Figure 6. The abscissa is the size of the S-phase, and the ordinate represents the corrosion degree which was expressed by the area ration of the adjacent corrosion pit and the core S-phase. It can be found that the corrosion degree monotonous decreases with the increment of the size of S-phase, namely the corrosion resistance of samples are positive correlated to the volume of secondary phase. There also exists well-defined relationship between the corrosion degree and the size of S-phase, which is shown as the black line in Figure 6 and Eq. (1) by function fitting with Origin 2018 software. With the increment of the volume of S-phase, the corrosion degree presents exponential decrement (the exponent factor $a<0$ ). In other words, the corrosion resistance is positive related to the volume of S-phase in Al-Zn-Mg-Cu alloy.

$$
C_{D}=7.137 x^{-0.31751}
$$

Where $C_{D}$ represents the corrosion degree. And $x$ is the area of S-phase.

\section{Corrosion behavior-phase distribution}

The corrosion morphology results of different kinds of phase distribution of samples after IC for $1.5 \mathrm{~h}$ is shown in Figure 7. It can be found that the corrosion cracks extended along the grain bound- 

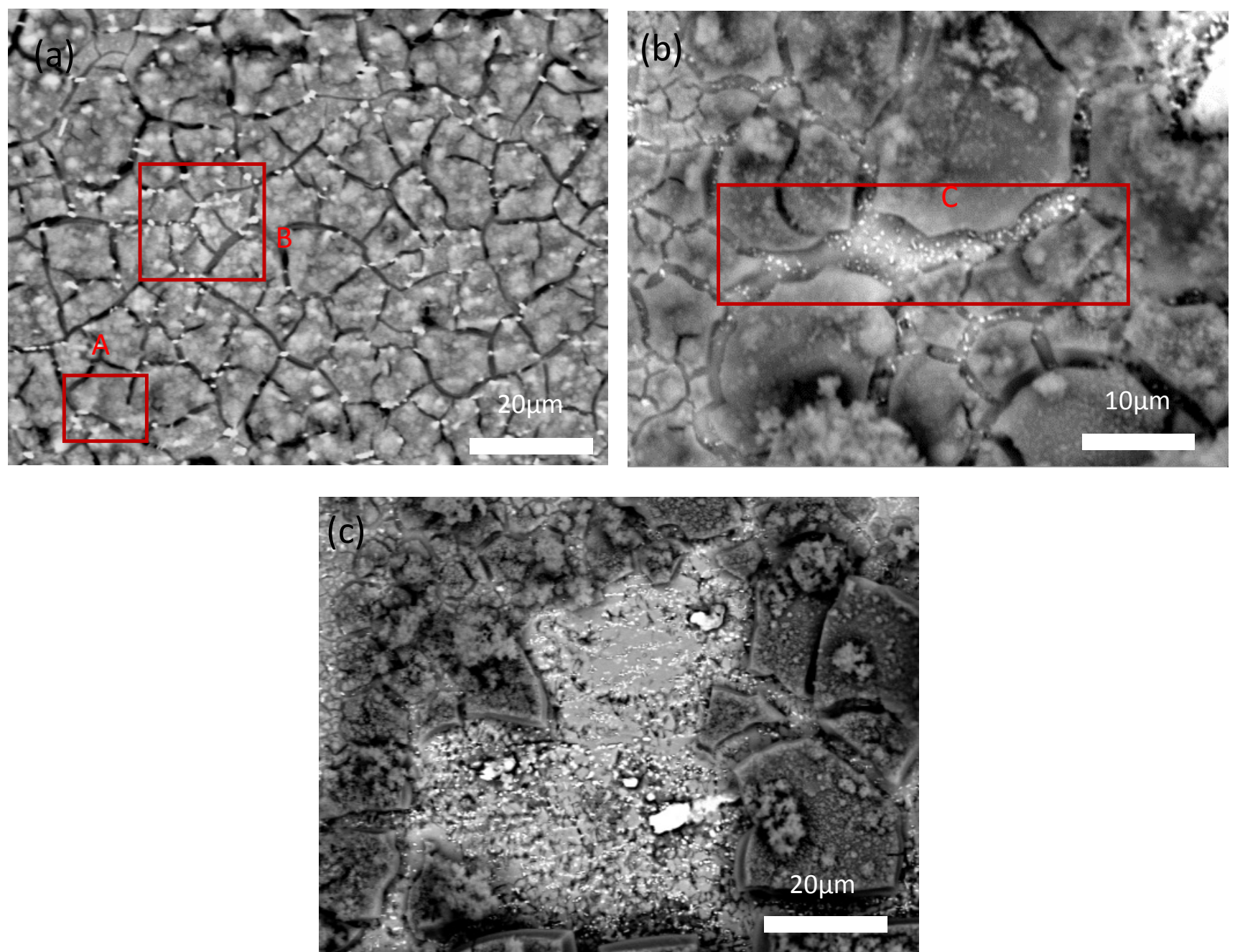

Figure 7: The morphology of corrosion for different kinds of phase distribution of samples after IC for $1.5 \mathrm{~h}$ (a) Uniform distribution; (b) Abundant precipitates in grain boundary; and (c) Abundant precipitate in local region.

ary and then forward to the position of "interconnection". The results show that the pits initiated homogeneously and extended along the grain boundary when the phase distributes uniformly in these regions (as shown in Figure 7a). However, it can be seen that there were some small discrepancies in these regions. For instance, the corrosion cracks didn't reach the point of "interconnection" in some regions where the distribution of phase is sparse (e.g. the red box marked " $A$ " in Figure 7a). The corrosion cracks have reached the point of "interconnection" in some regions where the distribution of phase is dense (as the red box marked " $B$ " shown in Figure 7a). Besides, the width of the corrosion cracks was also affected by the phase density in the grain boundary. The crack is exceptional wide in some regions where the phase is very dense in the grain boundary (e.g. the red box marked " $C$ " in Figure $7 \mathrm{~b}$ ). But the width of cracks is narrow in other regions where the phase distribution is sparse. What's more, when the phase density is exceptional large in local region (as the central gray region shown in Figure 7c), this region would act as the barrier that retard the corrosion cracks extend. From the corroded region in Figure 7c, it also can be deduced the dense phase distribution within grain also increase the corrosion resistance of alloy. Consequently, either the sparse or dense phase distribution increases the corrosion resistance of Al-Zn-Mg-Cu alloy.

\section{Discussions}

\section{Concentration-size relationship in secondary phase}

To further investigate the relationship between the content of main elements with the volume of constituent particles, the atomic concentration and size of 150 S-phases were collected with the assis- 


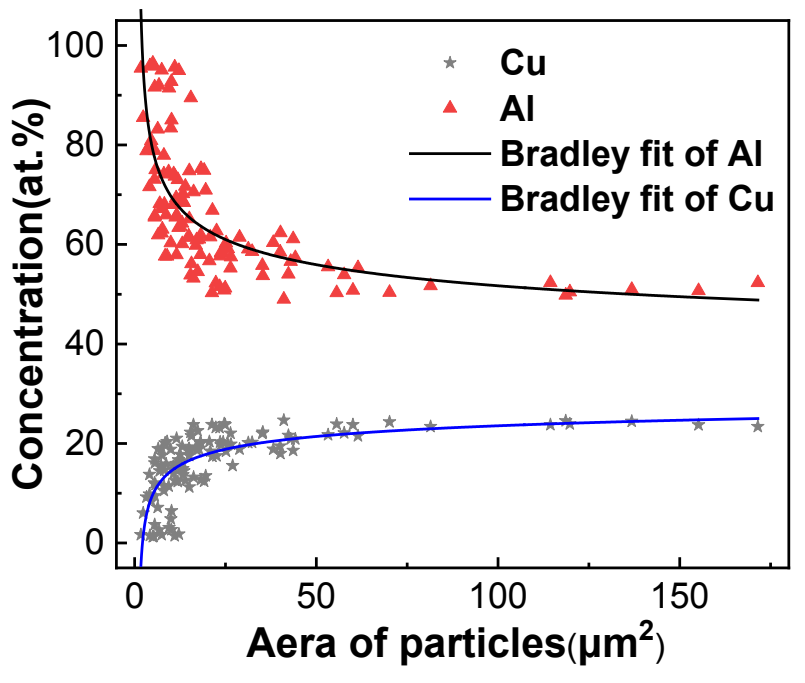

Figure 8: Relationship between the content of solute atoms in core of S-phase and the volume of S-phase.

Table 3: Bradley fitting of the concentration of $\mathrm{Al}$ and $\mathrm{Cu}$ varied with the area of S-phase.

\begin{tabular}{|l|l|l|}
\hline Element & Cu & Al \\
\hline Model & Bradley & Bradley \\
\hline Function & $\mathrm{y}=\mathrm{a}^{*} \ln \left(-\mathrm{b}^{*} \ln (\mathrm{x})\right)$ & $\mathrm{y}=\mathrm{a}^{*} \ln \left(-\mathrm{b}^{*} \ln (\mathrm{x})\right)$ \\
\hline $\mathrm{a}$ & 13.17 & -25.98 \\
\hline $\mathrm{b}$ & -1.30 & -0.03 \\
\hline Reduced Chi-Sqr & 20.65 & 83.97 \\
\hline
\end{tabular}

tant of SEM-EDS analysis and Image-pro plus software. Due to the content of $\mathrm{Mg}$ is basically equal to that of $\mathrm{Cu}$ in S-phase, the $\mathrm{Al}$ and $\mathrm{Cu}$ elements were chosen to determine the above-mentioned relationship. The results are shown in Figure 8. The abscissa is the area of S-phase, and the ordinate is the solute concentration in core of particles. It can be seen that the content of $\mathrm{Cu}$ is positively related to the volume of S-phase, but the content of Al turns out to be the opposite. The mathematical relationship between the content of main elements and the volume of particles is also well-defined. The result show that with the increment of the volume of S-phase, the content of $\mathrm{Cu}(\mathrm{Al})$ are shown as Bradley function increasing (decreasing), the fitting curve and function are shown as the black line in Figure 8a and Table 3.

The reason for this relationship between the concentration and the volume of S-phase is mainly related to the formation mechanism of intermetallic compounds. The essential of the secondary phase is a cluster of atoms, and mainly formed in the process of casting and corresponding heat treatments, so the larger the volume of particles, the higher concentration in the core position of secondary phase $[21,26,27]$. It also can be found that there are some data points deviating from the fitting curve in Figure 8. The possible reason is the effect of extremely irregular morphology of some phases on the experiment measurement.

The above content has revealed that the relationship between the concentration and size of S-phase, and the evolution law of atomic concentration in S-phase and surrounding region during the Intergranular Corrosion test. It can be concluded that the corrosion resistance of $\mathrm{Al}-\mathrm{Zn}-\mathrm{Mg}-\mathrm{Cu}$ alloy is positive related to the volume of S-phase. Except the propagation problem of corrosion crack [7], the more essential reasons are as follows: With the increment of the volume of S-phase, the content of $\mathrm{Cu}$ in S-phase also increased, so the equilibrium potential of the S-phase also increased, and the potential difference between the S-phase and surrounding matrix deceased, so the Intergranular Corrosion is more difficult to occur.

\section{Corrosion resistance-distribution relationship}

The results of electrochemical test showed that the corrosion resistance of the alloy first decreased and then increased and finally decreased with the solution time. The dissolution behaviors of secondary phase in the alloy during the solid solution stage has been studied in our previous work [21], the result shown that the dissolution of $n\left(\mathrm{MgZn}_{2}\right)$ phase mainly occurred when the alloy was suffered from solid solution process at $470{ }^{\circ} \mathrm{C}$ for $0 \sim 5$ min. During this stage, the corrosion resistance was nearly unchanged (the result has obtained in Polarization test). So, the corrosion resistance of the alloy with dispersed $\eta\left(M g Z n_{2}\right)$ phase is basically equal to its corresponding supersaturated solid solution. It was also known that the dissolution of $\mathrm{S}\left(\mathrm{Al}_{2} \mathrm{CuMg}\right)$ phase mainly occurred when the alloy was dissolved at $470{ }^{\circ} \mathrm{C}$ for $5 \sim 35 \mathrm{~min}$. During this stage, the corrosion resistance was first increased and then decreased with solution time, and the corrosion resistance reached highest value after solution for approximately $25 \mathrm{~min}$. According to research of other professors $[28,29]$, the possible reason is that the dissolution of S-phase simultaneously accompanied the process of recrystallization. The dissolution of $\mathrm{S}$ phase and the process of grain refinement would increase the resistance of alloy, 
but the process of grain growth is harmful for the corrosion resistance of the alloy. The dissolution of $S$ phase and the process of grain refinement mainly occurred when the alloy was dissolved at $470{ }^{\circ} \mathrm{C}$ for 5 $25 \mathrm{~min}$, so the corrosion resistance increased during this stage. However, the weakness effect of corrosion resistance caused by grain growth is more obvious when the alloy was dissolved at 470 ${ }^{\circ} \mathrm{C}$ for $25^{\sim} 30 \mathrm{~min}$, so the corrosion resistance of the alloy decreased during this stage.

As mentioned in section 5.4, either the sparse or dense phase distribution has the benefit influence on the corrosion resistance of $\mathrm{Al}-\mathrm{Zn}-\mathrm{Mg}-\mathrm{Cu}$ alloy. As we known, the corrosion rate of metal alloy is mainly controlled by the potential difference [30], and the potential difference is mainly contributed to the structure difference, such as: Concentration, grain structure, element types and other environment factors. When the phase distribution is sparse or dense in some regions, the atomic concentration difference in these regions are lower than that in other regions where the phase distribution is unevenly. So, the equilibrium potential difference is also low in these regions where the phase distribution is sparse or dense, besides, the corrosion initiating and extending in these regions also have a low rate. What's more, the local dense phase distribution region could be regarded as a "big phase" during immersion test. This region can act as anode at the pit initiating because of high content of $\mathrm{Mg}$ in $\eta\left(\mathrm{MgZn}_{2}\right)$ and $\mathrm{S}\left(\mathrm{Al}_{2} \mathrm{CuMg}\right)$ phase, then the "big phase" would act as the cathode with respect to the surrounding matrix when the de-Mg "big phase" was formed. So these regions can retard the corrosion initiating and extending during IC, and increase the corrosion resistance of Al-Zn$\mathrm{Mg}-\mathrm{Cu}$ alloy.

\section{Conclusions}

The effect of secondary phase on the corrosion of Al-Zn-Mg-Cu was investigated by using a nonheat treatment way to exclude the effect of grain size variation. About 150 samples were used to investigate the corrosion behaviors of secondary phase during Intergranular Corrosion test. Then the effect of size and distribution of secondary phase on the corrosion of this alloy was determined by using the SEM-EDS and EPMA equipment, Electrochemical test and the Image-pro plus software. What's more, the relationship between the composition of solute atoms and the volume of secondary phase, and the evolution law of atomic concentration in secondary phase and surrounding region during Intergranular Corrosion test was also studied. Some conclusions can be drawn as follows:

1. The atomic concentration of main elements in secondary phase is positively related with the volume of secondary phase.

2. The $\mathrm{Mg}$ atoms in $\eta\left(\mathrm{MgZn}_{2}\right)$ phase and $\mathrm{S}\left(\mathrm{Al}_{2} \mathrm{CuMg}\right)$ phase acts as anodic with respect to the $\mathrm{Al}$ matrix during the pit initiation, and preferentially dissolved to the Intergranular Corrosion solution, then the de-Mg $\eta$ phase ( $\mathrm{Zn}$ rich) and de-Mg S-phase (Cu rich) acts as cathode with respect to Al matrix. The $\mathrm{Al}_{7} \mathrm{Cu}_{2} \mathrm{Fe}$ phases acts as cathode with respect to the Al matrix during the $I C$ test.

3. The corrosion resistance of Al-Zn-Mg-Cu alloy is positive correlated to the volume of secondary phase.

4. Either the sparse or dense phase distribution on or within grain boundary has the benefit influence on the corrosion resistance of $\mathrm{Al}-\mathrm{Zn}-\mathrm{Mg}-\mathrm{Cu}$ alloy.

\section{Acknowledgements}

This work was supported by the Research on Key Technologies of inspection robot series- Topic 2: Development and application of indoor trackless power inspection robot based on multi DOF detection terminal (GDKJXM20185550). The authors would like to take this opportunity to express their appreciation.

\section{References}

1. P Zhou, Y Song, L Hua, J Lu, J Zhang, et al. (2019) Mechanical behavior and deformation mechanism of 7075 aluminum alloy under solution induced dynamic strain aging. Materials Science and Engineering: A 759: 498-505.

2. HX Li, QL Bai, Y Li, Q Du, L Katgerman, et al. (2017) Mechanical properties and cold cracking evaluations of four $7 \times x \times$ series aluminum alloys using a newly developed index. Materials Science and Engineering: A 698: 230-237.

3. R Pongen, AK Birru, P Parthiban (2019) Study of microstructure and mechanical properties of $A 713$ aluminium alloy having an addition of grain refiners Al-3.5 Ti1.5C and Al-3Cobalt. Results in Physics 13: 102105.

4. P Priya, DR Johnson, MJM Krane (2017) Precipitation during cooling of 7XXX aluminum alloys. Computational Materials Science 139: 273-284. 
5. A Azarniya, AK Taheri, KK Taheri (2019) Recent advances in ageing of $7 x x x$ series aluminum alloys: $A$ physical metallurgy perspective. Journal of Alloys and Compounds 781: 945-983.

6. KA Yasakau, ML Zheludkevich, MGS Ferreira (2018) Role of intermetallics in corrosion of aluminum alloys. Smart corrosion protection. Intermetallic Matrix Composites 2018: 425-462.

7. J Soltis (2015) Passivity breakdown, pit initiation and propagation of pits in metallic materials - Review. Corrosion Science 90: 5-22.

8. Z Szklarska-Smialowska (1999) Pitting corrosion of aluminum. Corrosion Science 41: 1743-1767.

9. S Dey, MK Gunjan, I Chattoraj (2008) Effect of temper on the distribution of pits in AA7075 alloys. Corrosion Science 50: 2895-2901.

10. C Meng, D Zhang, L Zhuang, J Zhang (2016) Correlations between stress corrosion cracking, grain boundary precipitates and $\mathrm{Zn}$ content of $\mathrm{Al}-\mathrm{Mg}$ - $\mathrm{Zn}$ alloys. Journal of Alloys and Compounds 655: 178-187.

11.A Chemin, D Marques, L Bisanha, AdJ Motheo, WW Bose Filho, et al. (2014) Influence of Al7Cu2Fe intermetallic particles on the localized corrosion of high strength aluminum alloys. Materials \& Design 53: 118-123.

12.J Wang, B Zhang, YT Zhou, XL Ma (2015) Multiple twins of a decagonal approximant embedded in S-Al2CuMg phase resulting in pitting initiation of a 2024Al alloy. Acta Materialia 82: 22-31.

13.Y Sun, Q Pan, Y Sun, W Wang, Z Huang, et al. (2019) Localized corrosion behavior associated with Al7Cu2Fe intermetallic in Al-Zn-Mg-Cu-Zr alloy. Journal of Alloys and Compounds 783: 329-340.

14.J Wang, B Zhang, B Wu, XL Ma (2016) Size-dependent role of $S$ phase in pitting initiation of 2024Al alloy. Corrosion Science 105: 183-189.

15.KD Ralston, N Birbilis, M Weyland, CR Hutchinson (2010) The effect of precipitate size on the yield strength-pitting corrosion correlation in $\mathrm{Al}-\mathrm{Cu}-\mathrm{Mg}$ alloys. Acta Materialia 58: 5941-5948.

16.Y Lu, AR Bradshaw, YL Chiu, IP Jones (2015) Effects of secondary phase and grain size on the corrosion of biodegradable Mg-Zn-Ca alloys. Mater Sci Eng: C 48: 480-486.

17.KA Unocic, P Kobe, MJ Mills, GS Daehn (2006) Grain boundary precipitate modification for improved intergranular corrosion resistance. Materials Science Forum 519-521: 327-332.

18.JG Brunner, N Birbilis, KD Ralston, S Virtanen (2012) Impact of ultrafine-grained microstructure on the corrosion of aluminium alloy AA2024. Corrosion Science 57: 209-214.
19.T Marlaud, B Malki, C Henon, A Deschamps, B Baroux (2011) Relationship between alloy composition, microstructure and exfoliation corrosion in $\mathrm{Al}-\mathrm{Zn}-\mathrm{Mg}$ -Cu alloys. Corrosion Science 53: 3139-3149.

20.N Birbilis, MK Cavanaugh, L Kovarik, RG Buchheit (2008) Nano-scale dissolution phenomena in $\mathrm{Al}-\mathrm{Cu}$ -Mg alloys. Electrochemistry Communications 10: 32-37.

21.Y Li, Y Deng, S Fan, X Guo, K Jiang, et al. (2020) An in-situ study on the dissolution of intermetallic compounds in the $\mathrm{Al}-\mathrm{Zn}-\mathrm{Mg}-\mathrm{Cu}$ alloy. Journal of Alloys and Compounds 829: 154612.

22.F Andreatta, H Terryn, JHW de Wit (2004) Corrosion behaviour of different tempers of AA7075 aluminium alloy. Electrochimica Acta 49: 2851-2862.

23. L Huang, K Chen, S Li (2012) Influence of grain-boundary pre-precipitation and corrosion characteristics of inter-granular phases on corrosion behaviors of an Al $-\mathrm{Zn}-\mathrm{Mg}-\mathrm{Cu}$ alloy. Materials Science and Engineering: B 177: 862-868.

24.AS El-Amoush (2011) Intergranular corrosion behavior of the 7075-T6 aluminum alloy under different annealing conditions. Materials Chemistry and Physics 126: 607-613.

25.LP Huang, KH Chen, S Li, M Song (2007) Influence of high-temperature pre-precipitation on local corrosion behaviors of $\mathrm{Al}-\mathrm{Zn}-\mathrm{Mg}$ alloy. Scripta Materialia 56: 305-308.

26.N Bayat, T Carlberg, M Cieslar (2017) In-situ study of phase transformations during homogenization of 6005 and $6082 \mathrm{Al}$ alloys. Journal of Alloys and Compounds 725: 504-509.

27.Y Sun, Q Pan, Z Huang, W Wang, X Wang, et al. (2018) Evolutions of diffusion activation energy and Zener -Hollomon parameter of ultra-high strength Al-Zn$\mathrm{Mg}-\mathrm{Cu}-\mathrm{Zr}$ alloy during hot compression. Progress in Natural Science: Materials International 28: 635-646.

28.NM Han, XM Zhang, SD Liu, DG He, R Zhang (2011) Effect of solution treatment on the strength and fracture toughness of aluminum alloy $\mathrm{Al}-\mathrm{Zn}-\mathrm{Mg}-\mathrm{Cu}$. Journal of Alloys and Compounds 509: 4138-4145.

29. R Sirichaivetkul, T Wongpinij, C Euaruksakul, C Limmaneevichitr, J Kajornchaiyakul (2019) In-situ study of microstructural evolution during thermal treatment of 6063 aluminum alloy. Materials Letters 250: 42-45.

30.N Pulido-González, B Torres, S García-Rodríguez, P Rodrigo, V Bonache, et al. (2020) Mg -1Zn -1Ca alloy for biomedical applications. Influence of the secondary phases on the mechanical and corrosion behaviour. Journal of Alloys and Compounds 831: 154735. 